\title{
A PESCA ARTESANAL E A CONSERVAÇÃO DA BIODIVERSIDADE DE PEIXES NO PANTANAL DE MATO GROSSO: A VOZ E O SILÊNCIO DAS PANTANEIRAS E DOS PANTANEIROS ${ }^{1}$
}

\author{
Silvano Carmo de Souza ${ }^{2}$ \\ Amadeu José Montagnini Logarezzi ${ }^{3}$
}

Resumo: este artigo faz parte de uma tese de doutorado de educação ambiental dialógico-crítica, cujo objetivo geral foi contextualizar a atividade pesqueira profissional artesanal em Cáceres no Pantanal de Mato Grosso a partir do diálogo igualitário com pescadoras/es, de modo a promover, simultaneamente, processo de formação dialógico-crítica com aquelas pessoas, sobretudo a partir de seus contextos e a respeito deles, utilizando a metodologia comunicativo-crítica. Neste artigo tratamos dos saberes tradicionais pantaneiros e sua relação com a conservação da diversidade biológica de peixes. Identificamos, dialogicamente, que as/os pescadoras/es tradicionais têm grande interesse em contribuir tanto com a formulação quanto com a efetivação das políticas de conservação.

Palavras-chave: Educação Ambiental; Pescadores; Metodologia Comunicativo-Crítica.

\footnotetext{
${ }^{1}$ Este artigo divulga parte dos resultados de uma tese de doutorado (DE SOUZA, 2017) que aborda ainda questões teórico-metodológicas da dialogicidade e da racionalidade ambiental, além de aspectos socioculturais relativos ao exercício da atividade pesqueira tradicional no Pantanal de MT, da participação delas/es no âmbito da formulação de políticas públicas e da conservação da diversidade biológica de peixes

${ }^{2}$ Doutor em Ciências Ambientais - Ambiente e Sociedade, Professor no Instituto Federal de Educação, Ciência e Tecnologia de Mato Grosso - Campus Cáceres Professor Olegário Baldo. Laboratório de Educação e Gestão Ambiental. E-mail: silvano.souza@cas.ifmt.edu.br . Lattes: http://lattes.cnpq.br/5675542907837639
}

${ }^{3}$ Pós-doutor em sociologia, Professor titular aposentado da Ufscar e Professor no PPG em Ciências Ambientais da UfSCar. E-mail: amadeulogarezzi@gmail.com. Lattes: http://lattes.cnpq.br/6153358744019882 


\section{Introdução}

Nós precisamos resistir para manter nossa cultura. Eu não quero que nossa história vire lenda. Lenda não tem fato real, mas nossa tradição é real! Pintado ${ }^{4}$

As pescadoras e os pescadores profissionais artesanais tiveram uma importante atuação durante a constituinte de 1988. Além da luta pelos direitos fundamentais e sociais, atinentes à manutenção de sua cultura, promoção da sociobiodiversidade e ao exercício da atividade pesqueira artesanal, também militaram pela inserção de dispositivos legais que garantissem a conservação da biodiversidade brasileira. Segundo Diegues (1995, p. 135) a Constituinte da Pesca, como ficou conhecido o movimento que reuniu pescadoras/es entre os anos de 1986 e 1988, contribuiu significativamente para que importantes ecossistemas, como o Pantanal mato-grossense e o litoral brasileiro fossem declarados como regiões prioritárias para a conservação.

Comunidades tradicionais pesqueiras geram benefícios para toda a sociedade, tendo em vista promover tanto a manutenção de modos próprios ser, fazer e se relacionar com o território pantaneiro, como a resistência e luta pela manutenção da memória e proteção do patrimônio cultural, material e imaterial, tendo por base seus saberes tradicionais no uso sustentável dos recursos pesqueiros etc. A pesca profissional artesanal é essencialmente caracterizada por seu aspecto artesanal; a tradição, materializada nos instrumentos e técnicas de pesca, representa uma expressão fundamental de enfrentamento do mercado.

Para a realização dessa pesquisa de educação ambiental, comprometida com as perspectivas dialógico-crítica (LOGAREZZI, 2012) e transformadora (LOUREIRO, 2004), utilizamos a metodologia comunicativocrítica - MCC (GÓMEZ et al., 2006), que é fundada na ação dialógica de Freire (2004), no agir comunicativo de Habermas (2012) e na aprendizagem dialógica de Flecha (1997). Trataremos neste artigo da conservação da biodiversidade de peixes no Pantanal de Mato Grosso, considerando, para tanto, as vozes das/os pescadoras/es profissionais artesanais filiadas/os às duas agremiações de representação sediadas no município de Cáceres-MT.

Objetivamos, portanto, identificar em diálogo com pescadoras $/ \mathrm{es}^{5}$ profissionais artesanais quais são os elementos obstaculizadores (que servem a processos de colonização do mundo da vida) e transformadores (que servem

\footnotetext{
${ }^{4}$ Consensuamos, durante a apresentação do termo de consentimento livre e esclarecido, que as/os pescadoras/es serão identificadas/os por codinomes. A maioria delas/es escolheu nomes de animais e plantas do Pantanal.

${ }^{5}$ De acordo com Freire (2005), "mudar a linguagem faz parte do processo de mudar o mundo... a relação entre linguagem-pensamento-mundo é uma relação dialética, processual, contraditória." (p. 68). Neste sentido, optamos por utilizar aqui uma linguagem não sexista.
} 
a processos de resistência e enfrentamento à colonização) que dizem respeito à conservação da biodiversidade de peixes no Pantanal de Mato Grosso e às políticas públicas correlatas.

Destaque-se, desde já, que as/os pescadoras/es profissionais artesanais têm no conhecimento tradicional, cunhado em sua memória coletiva, uma de suas principais fontes de informação e de manutenção de sua cultura. Ao contrário do que é pretendido por diversos setores do mercado e de representantes de instituições estatais, a maioria delas/es demonstrou interesse em permanecer desenvolvendo a atividade de forma artesanal.

\section{Pescadoras/es profissionais artesanais: os sujeitos da pesquisa}

Tem vários tipos de profissionais [...] Nós somos tradicionais. Eu e esses companheiros aqui realmente somos pantaneiros. Ariranha

No município de Cáceres a pesca profissional artesanal ${ }^{6}$ é desenvolvida por pescadoras/es vinculadas/os a duas instituições: a Colônia de Pescadores de Cáceres (Colônia Z-2) e a Associação de Pescadores Profissionais de Cáceres (Appec). São aproximadamente 580 filiadas/os à colônia e 300 à Appec (números de fevereiro de 2017). Esta atividade é desenvolvida de forma artesanal e ocorre majoritariamente no rio Paraguai e em seus afluentes, os rios Sepotuba, Jauru e Cabaçal. Do ponto de vista legal, a pesca profissional é desenvolvida de duas formas: industrial e artesanal; já a pesca não comercial é desenvolvida de três formas: desportiva, científica e de subsistência.

Diferente da pesca de subsistência - que não permite a comercialização -, a/o pescadora/or tradicional vende o seu pescado, que tem como destino principalmente o abastecimento da população local e regional. Identificamos que, apesar de muitas/os comercializarem o pescado em suas residências numa rede de solidariedade elaborada há décadas - ainda assim, a comercialização é exercida, expressivamente, por atravessadoras/es. A legislação prevê que a atividade profissional deve ser exercida de forma ininterrupta e exclusiva. Ininterrupta porque, para garantir seus direitos diante do Estado, ela/e deverá comprovar que exerceu a pesca durante todos os meses em que a atividade esteve liberada (período entre um defeso e outro); exclusiva porque a/o profissional artesanal não pode desenvolver outra atividade laboral, mesmo durante o período de defeso.

\footnotetext{
6 Para este artigo as/os pescadoras/es profissionais artesanais serão identificadas/os como pescadoras/es tradicionais. Esta designação se deu em função do consenso construído acerca desse tema durante a pesquisa, em cuja construção nossos diálogos consideraram os aspectos culturais que caracterizam a atividade.
} 
Ao discorrer sobre populações tradicionais, Diegues (2002) aponta que "apesar de poder, sob alguns aspectos, ser considerada uma categoria ocupacional, as/os pescadoras/es, particularmente as/os chamadas/os artesanais, apresentam um modo de vida particular" (p. 45), afirma ainda que as/os pantaneiras/os, a exemplo dos sujeitos dessa pesquisa, são fruto da miscigenação das tribos indígenas originais, com colonizadoras/es vindas/os do sudeste e com escravas/os negras/os. Para este trabalho adotaremos a noção de povos e comunidades tradicionais ${ }^{7}$, já que este conceito faz referência à luta incessante dessas pessoas pela permanência e/ou possibilidade de uso sociocultural de seus territórios ${ }^{8}$, trazendo, portanto, a discussão para o campo da justiça social (LITTLE, 2002). Também adotaremos como referência $O$ conceito de conhecimento tradicional adotado pelo Programa das Nações Unidas para o Meio Ambiente (PNUMA), para o qual o conhecimento tradicional é definido como

um corpo de conhecimento construído por um grupo de pessoas através de sua vivência em contato próximo com a natureza por várias gerações. Ele inclui um sistema da classificação, um conjunto de observações empíricas sobre o ambiente local e um sistema de auto-manejo que governa o uso dos recursos. (PNUMA, 2001, p. 5)

Diegues et al. (2000) trazem importantes contribuições para as reflexões que faremos nesse artigo, especialmente no que tange às relações entre ambiente, cultura, território e as lutas por direitos que caracterizam essas comunidades. Brandão e Leal (2012), em importante análise a esta obra, afirmam que o cenário descrito pelas autoras e autores é "o mais completo dentre os que procuram, de alguma maneira, caracterizar a comunidade tradicional e seus derivados". A partir disso o autor e a autora propõem inserir

\footnotetext{
7 Adotamos o conceito de povos e comunidades tradicionais da Política Nacional de Desenvolvimento Sustentável dos Povos e Comunidades Tradicionais, como previsto no artigo $3^{\circ}$, I "grupos culturalmente diferenciados e que se reconhecem como tais, que possuem formas próprias de organização social, que ocupam e usam territórios e recursos naturais como condição para sua reprodução cultural, social, religiosa, ancestral e econômica, utilizando conhecimentos, inovações e práticas gerados e transmitidos pela tradição. Nossa opção reside no fato de que esse conceito, além de ser fruto de um amplo processo dialógico do qual estes povos e comunidades participaram, também expressa a questão do auto reconhecimento, das formas próprias de organização e da transmissão de saberes pela tradição.
}

8 Adotamos o conceito de territórios tradicionais da Política Nacional de Desenvolvimento Sustentável dos Povos e Comunidades Tradicionais, como previsto no artigo $3^{\circ}$, II "os espaços necessários a reprodução cultural, social e econômica dos povos e comunidades tradicionais, sejam eles utilizados de forma permanente ou temporária [...]". Nossa opção reside no fato de que esse conceito, além de ser fruto de um amplo processo dialógico do qual estes povos e comunidades participaram, também expressa o caráter da temporalidade, característicos dos territórios das/os trabalhadoras/es com quem dialogamos. 
outros "qualificadores" que também identificam as populações tradicionais. Entre eles destacamos os que são densamente identificados nessa pesquisa: $a$ transformação da natureza, a autoctonia, a memória de lutas passadas de resistência, a história de lutas e de resistências atuais e a experiência da vida em territórios cercados e ameaçados.

Ao promover a manutenção da sociobiodiversidade pantaneira, a atividade pesqueira artesanal desenvolvida na região de Cáceres é contra hegemônica9 ${ }^{9}$. Como demostrado por De Souza e Logarezzi (2017; 2018b) há uma ética tradicional ribeirinha pantaneira que lhes garante, cotidianamente, condições empíricas de aproximações e luta por direitos e garantias. Diante disso, apesar de contribuir, substantivamente, com a manutenção e manifestação da cultura tradicional pantaneira, ser fonte de renda e de proteína tanto para as/os pescadoras/es como para a população residente nos bairros periféricos do município, essas/es pescadoras/es afirmam que são tratadas/os como invisíveis pelo poder público municipal.

\section{O giro dialógico no Pantanal de MT e a conservação da biodiversidade de peixes}

As/os pesquisadoras/es e educadoras/es que atuam com a metodologia comunicativo-crítica - MCC (GÓMEZ et al., 2006) têm sinalizado que, em função das mudanças ocorridas nas últimas décadas, a sociedade contemporânea tem se apresentado com diferentes denominações tais como sociedade da informação, sociedade do conhecimento e sociedade do risco. Para a autora e os autores,

em qualquer caso, estas diferentes concepções de sociedade compartilham um denominador comum, o diálogo, que se constitui uma nova categoria social inerente às relações sociais, influenciando em todos os âmbitos, tanto no econômico e político como no pessoal, familiar e social. (GÓMEZ et al., 2006, p. 11-12, grifo e tradução nossa)

\footnotetext{
${ }^{9}$ Para Gruppi (1978) o conceito de hegemonia adotado por Gramsci, em toda a sua amplitude "opera não apenas sobre a estrutura econômica e sobre a organização política da sociedade, mas também sobre o modo de pensar, sobre as orientações ideológicas e inclusive sobre o modo de conhecer" (p.3). Nesse sentido, entendemos que há uma movimento contra hegemônico, nos termos gramscianos, nos enfrentamentos cotidianos empreendidos pelas/os pescadoras/es tradicionais no Pantanal de Mato Grosso, especialmente, no que trata da defesa de sua cultura.
} 
informação passa a ser elemento central nas relações humanas, sejam elas educacionais, trabalhistas, comerciais, políticas etc. e, também, tem implicações geopolíticas, tanto no âmbito local quanto global, inaugurando um novo paradigma societário, o da sociedade da informação.

Diante disso, grupos de interesses diversos, especialmente os envolvidos em conflitos socioambientais (LAYRARGUES 2006), como as pescadoras/es tradicionais com quem dialogamos nesta pesquisa, tendem a concentrar seus esforços na busca e processamento de informações com vistas a atender seus pleitos. Se, por um lado, setores de mercado impõem suas demandas, inclusive ocupando todas as instâncias do Estado - Judiciário, Executivo, Legislativo e Ministério Público -, por outro, setores populares se articulam em movimentos não institucionalizados e/ou através de pessoas jurídicas de direito privado (associações, colônias de pescadoras/es, cooperativas e sindicatos) com fins de se oporem às condições de opressão às quais são submetidas/os. Ao tomarem conhecimento de seus direitos e deveres, aquelas/es que eram/são tidas/os como seres menos pelo projeto societário capitalista, além de ter a oportunidade de decidir sobre suas vidas, passam, do mesmo modo, a questionar de forma consistente as arbitrariedades cometidas pelo Estado e pelo mercado.

Há evidenciado, portanto, um giro dialógico (AUBERT et al., 2008, p. 33), a partir do qual as pessoas se informam e criticamente analisam sua realidade. Diante desse processo passam, então, a questionar contratos, convenções e tratados, duvidar das imposições dogmáticas e da rigidez do pensamento (GADOTI, 2003, p. 16-23), questionar a burocratização e a instrumentação dos ambientes de aprendizagem pelas elites (GUTIERREZ, 1988 , p. 17 - 46) e a problematizar o distanciamento das políticas públicas de sua realidade (FREIRE; NOGUEIRA, 1989). Portanto, como apontado por Flecha, Gómez e Puigvert (2001), o giro dialógico tem repercussão na vida cotidiana das pessoas - na relação entre familiares, amigas/os, trabalhadoras/es e empregadoras/es - e, além disso, tem oportunizado uma maior participação daquelas/es que tradicionalmente tiveram seu direito de dizer e agir cerceado. Trata-se, seguramente, de uma característica que revela uma transformação substancial na sociedade, transformação esta que tem repercussão em todas as áreas da vida cotidiana, que exige, além de nossa atenção/reflexão, nosso movimento propositivo.

A despeito das intromissões oriundas das forças de mercado, esse giro dialógico tem propiciado a explicitação o interesse das/os pescadoras/es tradicionais de participarem dos processos de formulação de políticas públicas de conservação da biodiversidade de peixes no Pantanal de Mato Grosso. Dos relatos feitos durante os dois anos de convivência que tivemos para a realização dessa pesquisa, cotidianamente ouvimos seus argumentos que sempre tiveram alguma sugestão para a conservação dos peixes do Pantanal, mas que suas vozes foram caladas pelas forças do mercado, especialmente, pela indústria do turismo, pelo setor energético e pelo agronegócio. 
Eu e meus companheiros sempre participamos dessas reuniões [...] Igual àquela lá na câmara que falou das hidrelétricas[...] a gente fala, fala mas no final o que fica na lei é o que eles querem. Ninguém segurou a barragem lá do Jauru e nós éramos contra. Quem está pagando é a família [...] que moram a vida toda aqui no Limão e não conseguem mais viver do peixe. Curimbatá

Há consenso, pelo menos entre as oitenta e três pessoas com quem dialogamos, de que o conhecimento tradicional pantaneiro - dialógico e culturalmente elaborado - não foi considerado na formulação das principais políticas públicas de pesca a que estão submetidas/os. Exemplo disso fora identificado em dois de nossos grupos de discussão comunicativos. Nos encontros em que dialogamos sobre a legislação estadual de pesca - Lei no 9.096/2009 -, elas/es afirmaram que, apesar de exporem interesse, não haviam tido a oportunidade de participar ativamente de espaços consultivos e/ou deliberativos em que fora tratado da legislação em comento.

O que nós sabemos da lei? É que nós não podemos fazer nada do que fazíamos antes. Estão matando minha cultura. Mataram os índios e agora estão matando nossa cultura [...] Estão querendo tirar meu pendurão, mas será que ele mata mais do que essas barcaças subindo pra cá na Piracema? Ontem eu cobrei isso lá da reunião da Sema e ninguém me respondeu. Pataquinha

É difícil vir alguém do governo aqui na colônia falar pra nós de lei. Quando vem, só fala o que nós não podemos fazer [...]. Ninguém fala de nossos direitos [...] porque será? Eu fiquei em pé naquela reunião, pra cobrar os meus direitos, mas a [...] pediu o microfone e não deixou eu falar. Não tem problema, agora nós somos um grupo mais unido e nós vamos cobrar nossos direitos. Beija Flor

Como demonstrado por De Souza e Logarezzi (2017), na contramão dessa inação estatal propositada, verificamos que é crescente o número de pescadoras/es tradicionais que, mesmo diante das dificuldades estruturais e circunstanciais pelas quais passam a categoria, têm se articulado objetivando participar dos espaços de diálogo, como os que coletivamente propusemos nessa pesquisa, a fim de, a partir desses ambientes dialogais, empreenderem ações que viabilizem as propostas pretendidas pelas comunidades com vistas à conservação da biodiversidade de peixes. 


\section{Considerações metodológicas e delineamento da pesquisa}

$\mathrm{Na}$ metodologia aqui utilizada (MCC), considera-se respeitosamente a voz de todas/os as/os envolvidas/os no processo investigativo, de modo a evitar o desnível epistemológico e a hierarquia interpretativa entre participantes de diferentes inserções sociais/culturais. Com isso, distinguem-se os papéis de pesquisador/a acadêmico/a e de pesquisador/a do contexto da pesquisa, ou popular, cujo encontro potencializa a produção do conhecimento dialógico, em que a elaboração teórica e a vivência prática interagem dialógica e dialeticamente, resultando numa práxis transformadora comprometida com os desafios apontados pelas pessoas do contexto, redundando ainda na perspectiva de coletivamente se fazerem sujeitos históricos, ao se fazerem valer da sistematização teórica acadêmica aliada à contextualização prática popular. Nessa perspectiva, utilizamos nessa pesquisa as técnicas de observação comunicativa, de entrevista em profundidade e de grupo de discussão comunicativo (p. 77-89).

Participaram de forma direta das atividades educativas 83 pessoas. Assim como nas demais fases do projeto, os sujeitos participaram ativamente da fase de análise dos dados, consolidando a ruptura com os desníveis epistemológicos e interpretativos. Procuramos identificar duas dimensões: a obstaculizadora - que configura barreiras que impedem ou dificultam a efetivação de maior igualdade social -, e a transformadora - que mostra as formas ou os caminhos de superação dessas barreiras. Diariamente as informações foram registradas em um caderno de campo e organizadas em matrizes de análise dispostas em temas, categorias, subcategorias e dimensões (Quadro 1).

Quadro 1: Sistematização geral dos dados.

\begin{tabular}{|c|c|c|c|c|}
\hline \multirow{4}{*}{ Dimensões } & \multicolumn{4}{|c|}{ Tema, categorias e subcategorias } \\
\hline & \multicolumn{4}{|c|}{ Conservação da biodiversidade de peixes } \\
\hline & \multirow{2}{*}{$\begin{array}{l}\text { Mundo da vida } \\
\text { Sujeito }\end{array}$} & \multicolumn{3}{|l|}{ Sistema } \\
\hline & & $\begin{array}{l}\text { Colônia Z-2 / } \\
\text { Appec } \\
\text { representação }\end{array}$ & Estado & Mercado \\
\hline Obstaculizadora & $\mathrm{COMS}$ & $\mathrm{COSr}$ & $\mathrm{COSe}$ & COSm \\
\hline Transformadora & CTMs & CTSr & CTSe & CTSm \\
\hline
\end{tabular}

A primeira letra da sigla se refere ao tema $(\mathrm{C})$, a segunda à dimensão ( $\mathrm{O}$ ou $\mathrm{T})$, a terceira à categoria (M ou S) e a quarta à subcategoria (s, r, e ou $\mathrm{m}$ ). 


\section{A pressão de pesca sobre espécies nobres ${ }^{10}$ : pressão do mercado e inação do Estado}

"Eu não quero passar fome, se o governo não ajuda, os atravessadores me ajudam e depois compram o meu peixe". Foi com esta frase que o pescador Cocha de Nego iniciou uma longa argumentação sobre os problemas que a categoria enfrenta em função das dificuldades de acesso às políticas de incentivo e fomento. Segundo os relatos das pessoas que participaram dessa pesquisa, as/os atravessadoras/es foram responsáveis pela aquisição de aproximadamente setenta por cento de todo o pescado comercializado por elas/es em 2014.

Elas/es apontaram que há uma crescente pressão sobre a pesca de espécies de maior valor comercial, especialmente pacu (Piaractus mesopotamicus), pintado (Pseudoplatystoma corruscans), cachara (Pseudoplatystoma fasciatu), piraputanga (Brycon hilarii) e, em menor escala, a pacupeva (Mylossoma paraguayensis) e o piavussu (Leporinus macrocephalus). Algumas/uns afirmam que iniciaram sua carreira pescando outras espécies - tidas como não nobres -, mas que ao notarem que o mercado não absorvia estes produtos mudaram suas estratégias de pesca e passaram a depender do subsídio para o exercício da atividade. Em função disso, identificamos que há uma dependência financeira umbilical de grande parte das/os pescadoras/es tradicionais em relação à atuação de atravessadoras/es. A exemplo de outros sujeitos da pesquisa, em um de nossos primeiros encontros a pescadora Piraputanga afirmou que

os compradores de peixes [atravessadoras/es] são um presente de Deus pra nós. Eles nos ajudam com a gasolina, com o gelo, ajudaram o Bagre Cabeçudo a reformar o barco. Agora que a pesca abrir a gente já vai conseguir pagar esse empréstimo com o peixe lá de baixo. Piraputanga [COMs]

10 Durante os encontros em que dialogamos sobre as ações do mercado e a pressão de pesca sobre "peixes nobres" elas/es afirmaram que não sabiam a origem dessa denominação, mas que não tinham dúvidas de que era uma invenção dos comerciantes. Diante disso consensuamos que em nossas atividades chamariamos estas espécies de "peixes de maior valor comercial". 
pelos peixes de maior valor comercial. Tanto as/os atravessadoras/es quanto as/os consumidoras/es finais preferem estas espécies.

Eu sei que isso é ruim para o meio ambiente, mas a maioria de nós aqui desse grupo somos pescadores de Pacu e de Pintado, somente dona [...] Jurupensem [COSm]

Às vezes eu saio para pegar uns piavussu. Se tivesse ajuda do governo, ou algum curso, nós poderíamos deixar esses peixes grandes descansar e partir para esses peixes mais fracos [...]. Ferreirinha [COSe]

Durante os encontros em que tratamos da questão pressão da pesca, ao falarem sobre a ação de atravessadoras/es, relataram que o governo deveria promover a cadeia produtiva de espécies de menor valor comercial

O povo mais antigo ainda come esses peixes mais simples, do tipo do bagre, da piranha [...], mas a maioria só quer o pacu e o pintado. Esses restaurantes só querem esses peixes [...] é atrás deles que a gente vai. Mutum [COSm]

Eu só pesco outros tipos de peixe se não tiver como ir lá pra baixo, esses outros quase não tem valor, só dá trabalho pra gente. [...] A prefeitura nunca fez nada pra ajudar a gente vender esses tipos mais ruim de peixe! Piau [COSe]

O processo exercido por atravessadoras/es promove um círculo vicioso que fragiliza a categoria e impõe a pressão de pesca sobre peixes de maior valor comercial. Vejamos porque: a) parte significativa dos territórios de pesca próximos à cidade foi ocupada por pescadoras/es amadoras/es com a construção ilegal de ranchos e pousadas e afixação de tablados para o uso criminoso de ceva fixa; b) diante disso, as/os pescadoras/es tradicionais precisam ir a locais mais distantes da cidade para buscar este pescado; c) estas viagens são dispendiosas e, necessariamente, precisam ser subsidiadas; d) em função da inação do Estado, a ação de atravessadoras/es é permanente; e) ao subsidiarem a atividade elas/es dão preferência a estas espécies; f) atravessadoras/es determinam o preço a ser pago no quilo do pescado e, assim, retroalimentam esse sistema desumanizante, escravagista e ecologicamente insustentável.

Entre as formas de enfrentamento a esta questão - identificadas nas três técnicas de coleta de dados - consensuamos que deveríamos aprofundar nossos diálogos sobre as redes de solidariedade já existentes no grupo. Como demostrado por De Souza e Logarezzi (2017), existe uma tímida, mas importante rede de solidariedade de comercialização do pescado artesanal. Trata-se de uma estratégia desenvolvida, ao longo de décadas, por 
pescadoras/es que decidiram não entregar parte do fruto de seu trabalho nas mãos de atravessadoras/es.

Para subsidiar nossos diálogos sobre esse tema, utilizamos como referência o texto de Singer (1997). Procuramos dialogar mais detidamente sobre: sistemas de crédito, processos produtivos solidários e sustentáveis, cooperação, autogestão, consumo solidário e sustentável, redes de trabalho, cooperação e articulação. Especialmente após os processos de validação das entrevistas e ao final dos encontros em que tratamos, especificamente, sobre as propostas de enfrentamento à pressão do mercado - como estratégia de conservação da biodiversidade de peixes -, elas/es apontaram que a categoria deve: a) fortalecer os laços de amizade e fraternidade existente entre as/os pescadoras/es filiadas/os às duas agremiações; b) fortalecer as redes de informação e comercialização já existentes e, a partir delas, promover a criação de outras redes; c) propor à colônia e a associação a formalização de denúncia ao Ministério Público Federal com vistas a reforçar a fiscalização sobre o cumprimento de cotas e a comercialização de pescado realizado por pescadoras/res amadoras/es; c) estabelecer como proposta a ser apresentada à diretoria, tanto da colônia quanto da associação, a necessidade de promover espaços de diálogo com o núcleo de economia solidária da Unemat, com vistas a proposituras de ações conjuntas; d) retomar os diálogos com as agências de fomento, a fim de negociar coletivamente as dívidas; e e) pleitear junto ao ICMBio e à Sema a criação de uma unidade de conservação de uso sustentável.

\section{A criminalização da atividade pesqueira artesanal: estratégia de ocultação da inação propositada do Estado e dos crimes do mercado}

É mais fácil colocar a culpa na gente do que culpar quem planta soja e desmata as nascentes de nossos rios [...] é mais fácil culpar os mais fracos. Beija Flor (CTMs)

11 Em reunião realizada no mês de janeiro de 2016 com a presença de vinte dois pescadores e seis pescadoras, vinculadas/os às duas agremiações, somente quatro deles e duas delas haviam recebido o seguro defeso que deveria ter sido pago ainda no mês de novembro de 2015. Segundo a Federação de Pescadores de Mato Grosso, esse atraso ocorreu, principalmente, em função de mudanças na legislação federal.

Revbea, São Paulo, V. 14, № 4: 120-142, 2019. 
sobre a proposta de moratória da pesca, empreendida por Maggi no Senado Federal; a dificuldade de acesso a políticas de incentivo e fomento, a concorrência com o pescado oriundo da aquicultura de grande escala e da comercialização de pescado oriundo da pesca amadora.

Em reuniões oficiais, promovidas por instituições privadas e estatais, é cada vez mais comum ouvirmos relatos de técnicas/os de órgãos ambientais e de representantes de setores vinculados ao mercado que as/os pescadoras/es tradicionais são em grande medida responsáveis pela diminuição do estoque pesqueiro em algumas regiões do Pantanal mato-grossense. Em função do avanço da aquicultura na região Centro-oeste, especialmente em Mato Grosso, também tem sido recorrente o pronunciamento de representantes de instituições públicas que defendem a migração forçada (uma espécie de higienização do rio) da atividade pesqueira artesanal para a prática da piscicultura. Entretanto, ao dialogarmos sobre essa possibilidade, cerca de 6\% (cinco de oitenta e três) das/os participantes dessa pesquisa sinalizaram este interesse.

Esse negócio de criar peixe é pra fazendeiro e pra sitiante, eu sou pescadora tradicional. Eu respeito o meu peixe, eu até sei outra profissão, mas abandonei e hoje vivo nesse pantano pescando. Eu aprendi usar a linhada com meu pai e com minha mãe, eu não quero nem de longe esse negócio de criar peixe. Onça [CTMs]

Tanto quanto para a promoção da pesca profissional artesanal, é inegável que o Estado deve investir na piscicultura familiar nessa região de Mato Grosso. Dados de 2014, oriundos do Instituto Mato-grossense de Economia Agropecuária - Imea -, apontam para a necessidade de investimentos em pesquisa e linhas de crédito que promovam a sustentabilidade socioambiental da cadeia produtiva, também dos produtos da aquicultura. Entretanto, como identificamos em diálogo com pescadoras/es tradicionais, há entre elas/es, o interesse majoritário em permanecer desenvolvendo a atividade artesanal, já que esta, mais do que fonte de renda, representa a expressão de sua cultura pantaneira - e de seu mundo da vida. Para tanto, como já dito, reivindicam que o Estado promova políticas públicas de pesca e conservação da biodiversidade de peixes que respeitem os direitos dos povos e das comunidades tradicionais pantaneiras.

\section{Diálogos sobre a fiscalização: explicitação das contradições sociais}

Enquanto dialogamos sobre a fiscalização e as normas que regulamentam esta ação estatal, procuramos problematizar este tema a partir de suas experiências cotidianas e do que há de previsão legal - tanto no texto constitucional quanto nos dispositivos infraconstitucionais -, identificando os elementos transformadores e obstaculizadores atinentes à conservação da biodiversidade de peixes. Um dos instrumentos de gestão dos recursos 
pesqueiros que mais afetam suas vidas é a ação do Estado através da fiscalização. Ao lado do conjunto de normas que estabelecem as medidas mínimas de captura, o período de defeso, a regulamentação do uso de apetrechos e as cotas máximas de captura, a fiscalização se destaca como sendo um dos instrumentos que mais influem no seu dia a dia. A partir desse diagnóstico inicial, realizado ainda durante a observação comunicativa, dialogamos com elas/es sobre a importância socioambiental desses instrumentos de gestão.

$\mathrm{Na}$ região onde estas pessoas pescam, atuam de forma permanente pelo menos oito órgãos de fiscalização: Polícia Militar Ambiental, Juizado Volante Ambiental (Juvam), Secretaria Estadual de Meio Ambiente (Sema), Marinha, Exército, Polícia Federal, Grupo Especial de Fronteira (Gefron) e Instituto Chico Mendes da Biodiversidade (ICMBio). Segundo elas/es as instituições com as quais a comunidade mantém contato cotidiano são com agentes da Sema, Polícia Militar Ambiental, Juvam, ICMBio e com a Marinha.

Entretanto, é importante consignar que, apesar do reconhecimento positivo acerca da importância da ação do Estado por meio destas instituições, é alarmante o número de denúncias que elas/es fazem no que diz respeito a ação e/ou inação do Estado no que tange ao cumprimento do estrito dever legal quando da execução do ato fiscalizatório. Foi desafiante dialogar sobre a fiscalização, especialmente porque, apesar de desde o início de nossas atividades de pesquisa elas/es já destacarem a importância deste instrumento de gestão, diziam preliminarmente que a gente não gosta de falar disso (Vitória Régia) [COSe], deixe esse povo [fiscais] pra lá (Flor de Aguapé) [COSe]; eu fico muito tempo sozinho lá pra baixo, não gosto de falar disso (Vagalume) [COSe]; e tem pai de família aqui que já apanhou inocente desse povo (Ariranha) [COSe]; é muito difícil ter confiança na polícia. Só quem já sofreu na mão desse povo, quem já fui humilhado que nem eu pra falar isso pro senhor. Aqui na cidade é uma coisa lá no rio é outra! Surubim [COSe]; estou nesse rio há mais de trinta anos e já comi o pão que o diabo amassou na mão desse povo. Hoje mudou um pouco, mas antes a gente nem sabia que tinha essas leis e o pau já comia [...]! Cachara [COSe]

Diante desses e de inúmeros outros argumentos nesse mesmo sentido, verificamos que de fato esse seria um tema ao qual retornaríamos somente se fosse demandado por elas/es. Com o passar do tempo, ao nos aproximarmos dialogicamente em confiança e, a partir daí, vislumbrarmos que através do diálogo poderíamos identificar formas de enfrentamento e de superação dos obstáculos que se apresentavam, elas/es se dispuseram a dialogar sobre essa temática de forma espontânea, crítica e propositiva. Nos termos de Freire (2004), podemos dizer que a situação-limite percebida e destacada deixou de ser vista como um obstáculo intransponível - um limite entre o ser e o nada! para ser vista como um freio ao processo de emancipação das pessoas e da comunidade - um limite entre o ser e o Ser Mais! (p. 94-95). 
Para as/os pescadoras/es com quem dialogamos, é fundamental que a fiscalização não se limite ao exercício do poder de polícia na estrita acepção da atribuição normativa. Mas que, além disso, atividades educativas ambientais, também previstas na legislação, sejam desenvolvidas, inclusive em parceria com a colônia e com a associação. Há uma evidente disposição, especialmente por parte das/os trabalhadoras/es mais experientes, em estabelecer parcerias e compartilhar saberes, por entenderem que sua cultura está sendo diariamente ameaçada em função, especialmente, da ação explícita e/ou silenciosa empreendida pelo Estado em retirá-las/os do rio.

Como já demostrado por De Souza e Logarezzi (2017; 2018a), em função das condições ecológicas da região - regidas pelo pulso de inundação -, para as pescadoras/es tradicionais que atuam nos rios do Pantanal Norte o território é dinâmico, o movimento das águas - culturalmente respeitado por elas/es - dita seu modo de vida e consequentemente a ocupação dos melhores locais de pesca. Observamos que o movimento tradicional que elas/es realizam na busca do pescado, somente tem sido garantido até hoje em função do respeito que existe entre elas/es. Há uma ética tradicional ribeirinha pantaneira (DE SOUZA; LOGAREZZI, 2017; 2018b), tecida em sua historicidade a partir da pluralidade de sentidos que elas e eles dão a sua coexistência com o Pantanal. O Estado deve garantir, portanto, no conjunto de normas que tratam de sua atuação, a manutenção dessa ética substancialmente tradicional.

Diante disso, todas as pessoas que participaram de nossa pesquisa discorreram longamente acerca das perdas de território que elas/es vêm sofrendo e a evidente inoperância do Estado diante desse fato. Trata-se da construção de ranchos e pousadas, da fixação de tablados (que todos sabemos são usados para uso de ceva fixa) em locais que historicamente foram utilizados por pescadoras/es tradicionais, hoje ocupados irregularmente por amadoras/es. A demanda apresentada por elas/es não é, pelo menos nesse ponto, por exclusividade para a região da pesca, mas para que o Estado garanta que elas/es também possam pescar onde memoravelmente exerceram a atividade.

No grupo de discussão comunicativo em que temos tratado da temática "perda de territórios tradicionais de pesca", consensuamos que ao participar desses ambientes de diálogo a categoria apresentaria quatro demandas: a) a manutenção dos acampamentos tradicionais já existentes, inclusive nas proximidades da Esec de Taiamã; b) que o Ministério Público promovesse um estudo da cadeia dominial da região, objetivando retomar o processo histórico de ocupação dessas áreas, a fim de garantir a memória dessas comunidades, c) que fosse ampliada a fiscalização sobre os tablados de pescadoras/es amadoras/es que insistem em utilizar cevas fixas, e d) que seja regulamentado o uso tradicional do tabuado. Estas demandas têm sido apresentadas e as/os profissionais da pesca esperam que sejam atendidas. 


\title{
Diálogos sobre a piracema e o período de defeso: é proibido para quem?
}

\author{
A piracema é por demais de importante, \\ mas não adianta muita coisa, porque é \\ nessa época que mais tem redeiros \\ nesse rio. Acari
}

A piracema é um processo ecológico natural que acontece em ciclos anuais e consiste na migração das espécies reofílicas em direção à cabeceira dos rios, onde buscam alimentos e condições adequadas para o desenvolvimento, principalmente das larvas e dos ovos. Dependendo do rio, em função das condições naturais locais que englobam principalmente o pulso de inundação, a desova pode acontecer ao longo do rio e não somente nas cabeceiras (ARENHART; MUNIZ, 2011). A fim de garantir o equilíbrio ecológico do ecossistema pantaneiro, a legislação de pesca do Estado de Mato Grosso Lei 9.096/1997 nos artigos 24, 27, 35 e 43 - estabelece as regras para o cumprimento do período de defeso nos rios da região. São duas as exceções a esta regra: a pesca de subsistência, realizada por povos e comunidades tradicionais ribeirinhas, e a pesca científica.

Ao dialogarmos sobre essa temática todas/os as/os pescadoras/es envolvidas/os na pesquisa afirmaram que é fundamental que tanto a pesca comercial, quanto a amadora sejam proibidas durante o período reprodutivo dos peixes. Trinta e seis entrevistadas/os $(90 \%)$ sustentaram que o período de defeso deveria iniciar no mês de outubro e não em novembro como tradicionalmente vem sendo estabelecido. Ainda vinte oito (70\%) defendem que, além da proibição da pesca, a navegação de motores acima de $15 \mathrm{hp}$ deveria ser proibida nesse período. Outro tema bastante relevante, diz respeito à permissão da pesca para subsistência; trinta e um entrevistadas/os $(77,5 \%)$ argumentaram que é necessário que o Cepesca ${ }^{12}$ reavalie o conceito de pesca de subsistência, já que para elas/es quem tem usufruído - pelo menos na região de Cáceres - dessa exceção são pescadoras/es amadoras/es, proprietários de sítios, chácaras e fazendas que ficam às margens dos rios da região e não as comunidades tradicionais, como prevê a legislação.

\footnotetext{
12 Além de nos debruçarmos sobre esse tema com cada uma/um das/os entrevistadas/os durante os encontros de validação das entrevistas, também realizamos dois encontros com cada Grupo de Discussão Comunicativo para tratar das atribuições do Conselho Estadual de Pesca (Cepesca). Nesses encontros também dialogamos sobre a importância da participação efetiva da categoria nesse espaço consultivo e deliberativo de governança. Como material de referência para estes encontros utilizamos a Lei 9.096/1997; que versa sobre esse tema entre os artigos $5^{\circ}$ a $8^{\circ}$.
} 
Esses fazendeiros daqui do [...] não são tradicionais, está errado. Se vai liberar tem que ter fiscalização para saber quem é tradicional mesmo [...]. Nós somos tradicionais, mas não podemos pescar na piracema? Isso está errado. Eu não pago meus remédios com esse seguro. Esse conselho (Cepesca) tem que mudar isso daí! Caravaçu [CTMs]

O relato de Caravaçu representa uma preocupação destacada pela maioria dos sujeitos da pesquisa. Sobre este aspecto, elas/es argumentam que o Estado deve ampliar a fiscalização durante este período, promover ações educativas e, também, reavaliar - de forma participativa - a possibilidade de inclusão de profissionais artesanais que vivem exclusivamente da pesca, já que muitas/os delas/es são, originariamente pescadoras/es de subsistência e se profissionalizaram para fins de garantias trabalhistas e previdenciárias. Apesar de sustentarem que o período de defeso é importante, discorreram longamente sobre as limitações desse instrumento de gestão. Sobre a conservação da biodiversidade de peixes na Piracema, além desses aspectos, houve consenso de que deveríamos registrar para fins de encaminhamentos junto às agremiações e aos órgãos públicos os seguintes elementos obstaculizadores e respectivas propostas de enfrentamento - como sintetizado no Quadro 2.

Quadro 2: Sistematização dos dados relativos ao período de defeso.

\section{Conservação da biodiver \\ Obstaculizadoras \\ rede de comercialização de pescado (peixe e jacaré) entre as/os atravessadoras/es que aliciam pescadoras/es tradicionais vulneráveis financeiramente e pescadoras/es amadoras/es}

uso irregular das declarações de estoques pesqueiro durante o período de defeso

comercialização crescente do pescado nas regiões mais distantes do perímetro urbano, especialmente no período noturno

em função da proibição da pesca do Dourado (Salminus brasiliensis) é crescente a facilidade de sua captura para fins esportivos; é crescente o número de amadoras/es que praticam o pesque e solte durante o período defeso

\section{Transformadoras ${ }^{\star}$}

- Estado deve ampliar a fiscalização e desenvolver atividades educativas durante a piracema, como forma de envolver as/os pescadoras/es tradicionais e amadoras/es em ações de conservação

além de ampliar a fiscalização, o Estado deverá implementar a afixação de tarja de identificação no pescado declarado no final de cada temporada de pesca

- Estado deve ampliar a fiscalização, especialmente nos pontos tradicionalmente já conhecidos de comercialização do pescado irregular

- Estado deve ampliar a fiscalização, especialmente nos pontos tradicionalmente já conhecidos de pesca esportiva 
...continuação.

\section{Conservação da biodiversidade - Piracema: Dimensões de análise Obstaculizadoras}

a fiscalização é insuficiente, especialmente no período noturno e nas regiões mais distantes do perímetro urbano

não foram convidadas/os para dialogar sobre a melhor época para o estabelecimento do período de defeso

o baixo valor do seguro defeso e o impedimento de que elas/es possam desenvolver qualquer outra atividade laboral

o período de defeso tem iniciado com pelo menos um mês de atraso, sustentam que, a depender do pulso de inundação, para algumas espécies como: pacu (Piaractus mesopotamicus; ), pacupeva (Mylossoma paraguayensis), piraputanga (Brycon hilarii), pintado (Pseudoplatystoma corruscans), piauvucu (Leporinus macrocephalus), deveria iniciar no mês de outubro

\section{Transformadoras ${ }^{\star}$}

além da necessidade urgente da ampliação, qualificação técnica e humanitária do quadro de servidoras/es, o Estado deve atuar em parceria com as instituições de representação de usuárias/os

grupos de diálogos consultivos permanentes devem ser criados, especialmente pela Sema e pelo ICMBio em Cáceres

- Estado deve proceder o recadastramento das/os pescadoras/es para que, de fato, somente as/os que vivem da atividade pesqueira tradicionalmente possam receber o seguro;

sustentam que, a partir disso, a categoria deve permanecer mobilizada para pleitear 0 aumento do valor do seguro defeso e/ou a liberação para que possam realizar alguma atividade remunerada durante esse período

- Cepesca deve promover espaços permanentes de diálogo com a categoria, a fim de juntas/os reestabelecerem as datas do período proibitivo;

sustentam que o Estado deve garantir o pagamento do seguro defeso antes de fazer a mudança da data

* As questões descritas neste quadro são sugestões de enfrentamento aos elementos obstaculizadores à conservação da biodiversidade de peixes durante a piracema.

A partir das vozes das/os participantes dessa pesquisa, restou-nos evidente que o estabelecimento do período de defeso, ao lado dos demais instrumentos de gestão, é um importante mecanismo de conservação da biodiversidade. Entretanto, à luz do que nos disseram, o Estado deve mobilizar os diversos sujeitos que convivem nessa região, a fim de juntos aprimorarem este instrumento, dialógica, permanente e participativamente. 


\title{
Diálogos sobre os apetrechos de pesca: isso interessa a quem?
}

\author{
Querem tirar nosso pendurão porquê? Isso \\ interessa a quem? Tomara que não aconteça \\ igual quando tiraram o boião. Ninguém veio \\ conversar com a gente. Tiraram e pronto! Onça
}

Como já apontado por Da Silva e Silva (1995) e Diegues (2000) no Pantanal a vida é moldada pelo ritmo das águas. As/os pescadoras/es tradicionais que realmente vivem da atividade pesqueira tiveram suas vidas transformadas pelo ritmo das águas dos rios pantaneiros. Há uma racionalidade pantaneira. Seu modo de vida e suas crenças são explicitamente oriundos do processo histórico elaborado por seus ancestrais.

Suas técnicas de pesca foram elaboradas, também, a partir de um longo e seletivo processo de convivência com as centenas de espécies de peixes e demais seres que vivem na região. Entre os principais critérios apontados por elas/es nos processos de seleção dos apetrechos a serem utilizados, argumentaram que levam em consideração, principalmente: as condições do tempo (cor da água, temperatura, direção do vento); as fases da lua; a eficácia e a seletividade do apetrecho, bem como a diminuição do tempo de sofrimento do peixe. Eu uso o que judia menos do bicho, se eu sei que dá pra pegar com a linhada eu já uso logo e pronto [...] diferente desses amadores que não conhecem nada de pesca e ficam judiando dos bichinhos Chimburé [CTMs].

Tanto quanto no cotidiano da atividade pesqueira da pescadora Chimburé, verificamos que, apesar das dificuldades encontradas por elas/es no dia a dia do exercício da atividade pesqueira (o que nos remeteria à falsa ideia de que seriam facilmente seduzidas/os a utilizar apetrechos proibidos) a maioria delas/es persiste no uso dos apetrechos permitidos pela legislação. Acompanhamos também a prática de pesca irregular, com o uso de apetrechos vedados pela legislação e em locais e períodos proibidos. Quando dialogamos sobre isso o argumento de todas/os as/ repousava sobre questão financeira. Argumentaram que em função das dívidas adquiridas, especialmente com atravessadoras/es, precisavam completar suas cotas semanais.

A proibição do uso de alguns apetrechos de pesca é vista por elas/es como uma estratégia mercantil de fragilização da atividade artesanal. Trata-se de uma maneira, antes velada e hoje em dia explícita, de forçar estas comunidades a deixar de confeccionar seus instrumentos artesanais e passar a depender dos equipamentos produzidos pelo mercado. Exemplo disso foi a proibição do corte de algumas árvores tradicionalmente utilizadas para a confecção de canoa de um pau só (araputanga, cambará, chimbuva, guanandi, cedro rosa), do batelão (chimbuva, arapuganga, cedro rosa, cambará), e dos tabuados (araputanga, ipê, cambará, cedro rosa) utilizadas há mais de um século. Hoje em dia, a maioria das embarcações é confeccionada de madeira (pinho cuiabano, cambará vermelho, cedro alagoano, morcegueira, figueira), 
adquirida no comércio local e confeccionada por uns poucos pescadores, ou de alumínio, também adquiridas no comércio.

Outro exemplo, também de explícito desrespeito à cultura pantaneira é a tentativa de alguns setores de mercado em proibir o uso do Anzol de galho e do Pendurão. |Em 1997, ano da publicação da lei estadual de pesca, estas e outras técnicas - características da atividade artesanal - já eram permitidas; todavia com o advento da Lei № 9.794 de 30/07/2012 as técnicas foram proibidas. Somente depois de uma ampla mobilização destas comunidades é que este dispositivo foi revogado com a emissão da Lei no 9.895 de 07/03/2013 permitindo novamente o uso destes apetrechos.

Entretanto - agora no âmbito do Cepesca -, em função do processo de reformulação da política estadual de pesca, as/os conselheiras/os retomaram a discussão sobre a possibilidade de proibição do uso desses instrumentos. Aquelas/es que sustentam pela proibição do uso desses instrumentos apoiam seus argumentos, principalmente nos aspectos relacionados à segurança da navegação, em um evidente atentado à pesca tradicional. Nos diálogos em que tratamos desse tema e apresentamos o argumento utilizado notadamente pelas/os agentes de mercado, elas/es concordaram que existe a necessidade de retomar a regulamentação sobre as formas de uso, os locais e horário de fixação da do pendurão, da pendura e da pendurinha, bem como, a necessidade de dialogar sobre a quantidade de pendurões a serem utilizados por cada pescadora/or profissional. O pendurão é da nossa cultura, ajuda a marcar meu território, ali o turista tem que me respeitar, o que eles querem é que o turista pesque de dia e de noite onde a gente sempre pescou. Pacupeva [COSm].

Além de representarem dois dos principais apetrechos artesanais utilizados por estas comunidades, 0 anzol de galho e o pendurão são estratégias tradicionais de demarcação territorial que fazem parte do conjunto de acordos solidariamente construídos entre elas e elas. Como apontado por Da Silva e Silva (1995), Embrapa (2012) e De Souza e Logarezzi (2017), toda a atividade pesqueira artesanal no Pantanal gira em torno dos aspectos culturais característicos dessas comunidades. Tanto quanto a luta por território e o consequente respeito às tradições pantaneiras, a manutenção da posse e da possibilidade de uso de seus meios de produção tem sido uma de suas lutas históricas (SILVA, 1991; DIEGUES, 1995). Estas pessoas não questionam a importância dessas normas ambientais, mas repudiam e estão dispostas a enfrentar a postura antidialógica dos agentes públicos que insistem em propor e emitir estes dispositivos legais sem consultá-las/os. Também, em virtude do giro dialógico, há uma disposição crescente no interior destas comunidades em resistir e enfrentar setores do mercado e da academia que pretendem - em nome da conservação da biodiversidade - criminalizar e/ou invisibilizar a cultura dos povos e das comunidades tradicionais pantaneiras. 


\section{Algumas considerações}

A educação ambiental dialógico-crítica, como propusemos realizar, somente é possível mediante a intensa busca pelo cumprimento do compromisso firmado entre os sujeitos da pesquisa e, no caso, o pesquisador e as/os colaboradoras/es. Também a confiança e a reciprocidade são condições inafastáveis para realização da pesquisa. Diante dos contratempos que se sucederam nesse processo investigativo - especialmente relacionadas à dificuldade de sincronizar nossas agendas e enfrentamentos diversos -, somente é possível o cumprimento desse compromisso se as pessoas envolvidas no processo se sentirem tão responsáveis por sua consecução quanto a/o pesquisadora/or, gerando um forte engajamento de todas/os com a proposta. Daí a necessidade da formulação comunitária do projeto.

Como já dissemos, para que isso ocorresse, elas/es participaram ativamente de todas as etapas de nosso trabalho. Envidaram muitos esforços, inclusive deixando de ir pescar, participando de encontros aos finais de semana e feriados, de reuniões e eventos, para validar e interpretar transcrições oriundas da observação comunicativa e das entrevistas etc.

No contexto da sociedade da informação, a MCC propõe efetivamente que se parta de uma práxis desveladora e problematizadora da realidade, em que se transformam sujeito e mundo que dialeticamente compõem seu todo. Ao colocar o diálogo igualitário como elemento chave para todo o planejamento e a execução das atividades de pesquisa, a metodologia rompe com o "exclusivismo" do conhecimento científico predominante na sociedade capitalista e propõe a formulação comunitária do conhecimento dialógico. Trata-se, então, do rompimento com um paradigma de racionalidade, com uma forma de gerar conhecimento, com uma maneira de se relacionar com as pessoas, de se pronunciar no mundo. Nessa perspectiva, a pronúncia do mundo não emerge da valorização de desníveis epistemológicos, de hierarquias interpretativas, onde iluminadas/os detêm as chaves exegéticas e hermenêuticas de intepretação da realidade. Pelo contrário, toma-se por base a racionalidade ambiental e comunicativa, em que se buscam as pretensões de validez nos processos de entendimento que ocorrem entre pessoas capazes de voz, entendimento e ação.

Nesse sentido, ao dialogarmos sobre a conservação da biodiversidade de peixes e as políticas públicas correlatas, os sujeitos dessa pesquisa argumentaram densamente sobre a importância de seus saberes tradicionais para essa temática no Pantanal de Mato Grosso. Como dito, essas comunidades têm no conhecimento tradicional, cunhado na memória coletiva, uma de suas principais fontes de informação e de manutenção de sua cultura e da sociobiodiversidade. Entretanto, diante da força do capital que avança sobre as águas pantaneiras, elas/es têm perdido territórios de pesca, vendo suas técnicas e apetrechos serem proibidos na legislação sem que sejam consultadas/os. 
Restou-nos evidente que para elas/es, a despeito de toda a contribuição que sua tradição tem dado à manutenção do equilíbrio ecológico pantaneiro, setores do mercado e algumas/uns agentes públicos - em nome de um conservacionismo indolente - cotidianamente expoliam sua cultura. Ao dialogarmos sobre o conjunto de instrumentos de políticas de gestão da pesca que mais Ihes afetam, elas/es enfatizam a importância de alguns deles (como por exemplo a fiscalização e o período de defeso), mas denunciam que o modus operandi adotado pelo Estado para a consecução desses instrumentos, além de desconsiderar as contribuições socioculturais da atividade pesqueira tradicional, privilegia setores do mercado que atuam criminosamente na região.

Em função da ação de atravessadoras/es e do aumento vertiginoso do número de filiadas/os nas duas agremiações - a maioria "pescadoras/es de seguro", segundo elas/es - as pessoas com quem dialogamos nessa pesquisa demandaram pela necessidade permanente de projetos e ações educativas que versem sobre as políticas públicas que tratam da conservação da biodiversidade. Reclamam pelo direito à participação comunicativa e pela garantia da incorporação de seus saberes nesses dispositivos legais. Finalmente, essa pesquisa de educação ambiental, consubstanciada nos referenciais teórico-metodológicos freiriano e habermasiano, permitiu ao grupo de pessoas participantes, além de identificar os elementos que obstaculizam os processos de libertação, também, viabilizar ações de enfrentamento e superação das situações limites em que vivem cotidianamente implicadas.

\section{Referências}

AGOSTINHO, A. A.; JÚLIO Jr., H. F. Peixes da Bacia do Alto Rio Paraná. In: Lowe-McConnell, R.H. Estudos de comunidades de peixes tropicais. Edusp, p. 374-400, 1999.

ARENHART, N. MUNIZ, C. C. Monitoramento reprodutivo de peixes reofílicos da bacia do Alto Paraguai: 2007/2008, 2008/2009, 2009/2010 e 2010/2011. Secretaria Estadual de Maio Ambiente de Mato Grosso. CFRP, 2011. $27 \mathrm{p}$.

AUBERT, A.; FLECHA, A.; GARCIA, C.; FLECHA, R.; RACIONERO, S. Aprendizaje dialógico em la sociedade de la información. Barcelona: Hipatia, 2008.

BRANDÃO, C.R. LEAL, A. Comunidade tradicional: conviver, criar, resistir. Revista da ANPEGE, v. 8, n. 9, p. 73-91, jan. /jul., 2012.

CASTELLS, M. Sociedade em rede. 8 ed., São Paulo: Paz e Terra. v. 1., 2005. DA SILVA, C. J. SILVA, J. A. F. No ritmo das águas do Pantanal. São Paulo: NUPAUB, 1995. 
DE SOUZA, S. C. Educação ambiental dialógico-crítica no Pantanal de Mato Grosso: a voz e o silêncio das pescadoras e dos pescadores tradicionais. Tese (Doutorado em Ciências Ambientais) - Universidade Federal de São Carlos, São Carlos, 2017. 300p.

DE SOUZA, S. C.; LOGAREZI, A. J. M. Educação ambiental dialógico-crítica comunidades tradicionais no Pantanal de MT: a solidariedade e os enfrentamentos nas práticas sociais. Ambiente \& Educação. Rev. de Educação Ambiental. v. 22, n. 1, p. 111-131, 2017.

DE SOUZA, S. C.; LOGAREZI, A. J. M. Educação Ambiental e participação comunicativa: diálogos com pescadoras/es artesanais no Pantanal de Mato Grosso. Revista Brasileira de Educação Ambiental. Revbea, São Paulo, $\mathrm{V}, 13$, No 1: 332-353, 2018a.

DE SOUZA, S. C.; LOGAREZZI, A. J. M. O exercício da liberdade na ética tradicional ribeirinha pantaneira amparado na dialogicidade e na criticidade: reflexões teóricas. Pesquisa em Educação Ambiental, Pesquisa em Educação Ambiental, vol.13, n.2 - pags. 101-116, 2018b.

DIEGUES, A.C. Pescadores artesanais e a questão ambiental. In: DIEGUES, A. C. (Org.). Povos e Mares. São Paulo: NUPAUB, 1995. p.131-137.

DIEGUES, et al. Saberes tradicionais e biodiversidade no Brasil. Brasília: Ministério do Meio Ambiente. São Paulo, 2000.

DIEGUES, et al. (org.) Povos e águas: inventário de áreas úmidas brasileiras. NUPAUB, 2002.

EMBRAPA. Pesca: uma atividade estratégica para a conservação do Pantanal, 2012. Disponível em: <http://www.cpap.embrapa.br/pesca/online/ PESCA2012 CPAP1.pdf>. Acesso em 10/06/2013.

FLECHA, R. Compartiendo palabras. Barcelona: Paidós, 1997.

FLECHA, R.; GÓMEZ; J. PUIGVERT, L. Teoría sociológica contemporánea. Barcelona: Paidós, 2001.

FREIRE, P. Educação como prática da liberdade. 22 ed. Rio de Janeiro: Paz e Terra, 1996.

FREIRE, P. Pedagogia da esperança: um reencontro com a pedagogia do oprimido. 22 ed. Rio de Janeiro: Paz e Terra, 2015.

FREIRE, P. Pedagogia do oprimido. 38 ed. Rio de Janeiro: Paz e Terra, 2004.

FREIRE, P. Política e educação. 5 ed. São Paulo: Cortez, 2001.

FREIRE, P. NOGUEIRA, A. Que fazer: teoria e prática em educação popular. Petrópolis: Vozes, 1989.

GÓMEZ, J. LATORRE, A, SÁNCHEZ, M. FLECHA, R. Metodologia comunicativa crítica. Barcelona: El Roure Editorial, 2006. 149 p.

GADOTI, M. Educação e poder. Introdução à pedagogia do conflito. 13 ed. São Paulo: Cortez, 2003. 
GUTIÉRREZ, F. Educação como práxis política. São Paulo: Sumus, 1988.

HABERMAS, J. Teoria do agir comunicativo. v. 1. Racionalidade da ação e racionalização social. Tradução: Paulo A. Soethe. São Paulo: WMF Martins Fontes, 2012.

INSTITUTO MATO-GROSSENSE DE ECONOMIA AGROPECUÁRIA - IMEA. Diagnóstico da Piscicultura em Mato Grosso. Cuiabá, 2014.

LAYRARGUES, P. P. Educação para a gestão ambiental: a cidadania no enfrentamento político do conflitos socioambientais. In: LAYRARGUES, P.P.; LOUREIRO, C.F.B.; CASTRO, R.S. (org.) Sociedade e meio ambiente: a educação ambiental em debate. 4 ed. São Paulo: Cortez, 2006.

LOUREIRO, C.F.B. Educação ambiental transformadora. Identidades da educação ambiental brasileira. Brasília: MMA, p. 65-84, 2004.

LIMA, A. M. Um estudo com pescadores pantaneiros de Cáceres - Mato Grosso: o rio Paraguai como elemento educativo. 2004. 103f. Dissertação (Mestrado em Educação e Meio Ambiente) - Universidade Federal de Mato Grosso, Cuiabá, 2004.

LITTLE, P. E. Territórios sociais e povos tradicionais no Brasil: por uma antropologia da territorialidade. Simpósio natureza e sociedade: desafios epistemológicos para a antropologia. Anais... 23 $3^{\underline{a}}$ Reunião bras. de antropologia. Gramado - RS, 2002. p. 2-31.

LOGAREZZI, A. J. M. Educação ambiental crítico-dialógica em comunidades de aprendizagem. In: MATHEUS, C. E. (org.). Educação ambiental: múltiplos olhares e saberes. São Carlos: Rima, 2012.

LUKÁCS, G. As bases ontológicas do pensamento e da atividade do homem. Temas de Ciências Humanas, v. 4, p. 1-18, 1978.

MUNIZ, C. C. Avaliação do papel do pulso de inundação sobre a riqueza e biodiversidade de peixes em ambiente inundável, no Sistema de Baías Caiçara, porção norte do Pantanal Mato-grossense, Alto Paraguai. 2010 82p. Tese (Doutorado em Ecologia).Universidade Federal de São Carlos. São Carlos-SP, 2010.

PNUMA, CBD/WG-ABS/1/3. Disponível em: <www.biodiv.org >. Acesso em: nov. 2007.

PORTO-GONÇALVES, C.W. A globalização da natureza e a natureza da globalização. 5 ed. Rio de Janeiro: Civilização Brasileira, 2013.

SILVA, L. G. Movimento social de pescadores no Norte e Nordeste brasileiros: tradição e mudança - 1966-1988. In: DIEGUES, A. C. (Org.) Encontro das Ciências sociais e o mar no Brasil. São Paulo/Belém, PPCAUB/Museu Paraense Emílio Goeldi/UFPA), 1991.

SINGER, P. Economia solidária: geração de renda e alternativa ao neoliberalismo. In: Proposta. São Paulo: FASE, 1997. 